\title{
Aprendizagem e relação professor- aluno na universidade: duas faces da mesma moeda
}

\author{
CENILZA PEREIRA DOS SANTOS* \\ SANDRA REGINA SOARES**
}

\section{RESUMO}

Este artigo apresenta parte dos resultados de uma pesquisa destinada a conhecer as representaçóes sobre a relaçāo professor-aluno no processo formativo, na universidade, de estudantes do último ano do Curso de Pedagogia de uma instituiçáo pública da Bahia que já atuam como professores. Aborda uma reflexão teórica sobre a aprendizagem e a relação professor-aluno. A investigaçáo, de natureza qualitativa com base nas representaçóes sociais, adotou como estratégia de coleta dos dados o memorial e a entrevista aberta. $O$ tratamento dos dados, firmado na análise de conteúdo, tipo temática (Bardin, 2000), permitiu constatar que as representações dos participantes sobre a relação entre professores e estudantes contemplam, de um lado, um discurso idealizado acerca do papel do professor, como mediador da aprendizagem e da participação ativa e comprometida do estudante, e, de outro, práticas estudantis baseadas na heteronomia, no medo de se expor e ser repreendido pelo professor. Essa significaçâo construída durante as vivências escolares foi reforçada pelas práticas vivenciadas na universidade que se distanciaram pouco das experiências anteriores e, dessa forma, não contribuíram, efetivamente, para a ressignificação de tais representaçóes. Palavras-chave: Universidades, Relaçóes professor-aluno, Representaçóes sociais, Avaliação qualitativa.

\footnotetext{
* Professora da Universidade do Estado da Bahia (Uneb); Doutoranda em Educação PPGE-UFBA (ceni_santos@yahoo.com.br).

** Professora adjunta da Universidade do Estado da Bahia (Uneb), Programa de Pós-Graduação em Educação e Contemporaneidade (PPGEDUC) (ssoares@uneb.br).
} 


\section{RESUMEN}

Este artículo presenta parte de los resultados de una investigación destinada a conocer las representaciones sobre la relación profesor-alumno en el proceso formativo, en la universidad, de estudiantes del último año del curso de Pedagogía de una institución pública de Bahia que ya actúan como profesores. Aborda una reflexión teórica sobre el aprendizaje y la relación profesor-alumno. La investigación, de naturaleza cualitativa con base en las relaciones sociales, adoptó como estrategia de recolección de datos el memorial y la entrevista abierta. La forma de tratar los datos, vinculada al análisis de contenido de tipo temática (Bardin, 2000), permitió constatar que las representaciones de los participantes sobre la relación entre profesores y estudiantes contemplan, de un lado, un discurso idealizado acerca del papel del profesor, como mediador del aprendizaje y de la participación activa y comprometida del estudiante, y del otro, prácticas estudiantiles basadas en una condición de heterónomo, en el miedo a exponerse y ser reprendido por el profesor. Esa significación construida durante las vivencias escolares fue reforzada por las prácticas vivenciadas en la universidad que se distanciaron poco de las experiencias anteriores $y$, de esta forma, no contribuyeron efectivamente para la resignificación de tales representaciones.

Palabras clave: Universidades, Relaciones profesor-alumno, Representaciones sociales, Evaluación cualitativa.

\section{ABSTRACT}

This article presents part of the results of a survey aimed at unveiling the representations involving the teacher-student relationship in the training process at the University, by senior students in the Pedagogy course of a public institution in the state of Bahia, students who are already working as teachers. It discusses a theoretical reflection on learning and the teacher-student relationship. The qualitative research was based on social representations, and adopted portfolios and open interviews as strategies for data collection. The processing of the data, based on content analysis, thematic type (Bardin, 2000), revealed that the participants' representations of the relationship between teachers and students include, on the one hand, an idealized discourse about the role of the teacher as a mediator of learning, and an active and committed participation of the student, and, on the other hand, student practices based on heteronomy, in fear of exposing themselves and being reprimanded by the teacher. This signification built along school life was reinforced by practices experienced at the University that were not too far from previous experiences and thus did not contribute effectively to resignifying such representations.

Keywords: Universities, Teacher-student relationship, Social representations, Qualitative assessment. 


\section{INTRODUÇÃO}

A relaçáo professor-aluno, na sociedade moderna, sempre foi alvo de tensão, desde que a escola se institucionalizou, principalmente com a função de preparar trabalhadores submissos e passivos, centrada numa concepção de aprendizagem mecânica, baseada na transmissão de conteúdos dogmatizados e descontextualizados (Enguita, 1989). Uma escola que dissocia as dimensóes afetivas, cognitivas, corporais do sujeito, na qual o foco do trabalho docente é a disciplina, a modelagem do comportamento do aluno, e não a aprendizagem significativa, a construção do conhecimento com sentido para a vida, a reflexão crítica, a argumentação e o diálogo entre alunos e professores. Essa escola sempre se apoiou na instalação do temor ao professor, à avaliação, às sançóes. $O$ temor à autoridade sempre foi garantia da ordem na classe e do empenho dos alunos na memorizaçáo dos conteúdos ensinados.

Nas últimas décadas, a relaçáo professor-aluno tem-se tornado mais complexa e tensa, em razáo do entrelaçamento de fenômenos contemporâneos diversos. $\mathrm{O}$ agravamento da desigualdade e da exclusão social e de outros problemas, em grande parte delas decorrentes, como a violência doméstica e social, a prostituição, o tráfico de drogas, afeta a vida das crianças e jovens e concorre para consolidar a descrença na escola como meio de ascensão social, e, dessa forma, a relação de autoridade-obediência fragiliza-se. Também, o desenvolvimento das tecnologias da informaçáo e da comunicação provocou uma reação em cadeia em todas as instâncias sociais, entre elas as educacionais. Uma avaliação do processo educativo dá a conhecer que, de um lado, os alunos são alcançados por uma avalanche de informaçóes, por meio da internet, de uma forma mais atrativa do que a tradicionalmente desenvolvida pela escola. Diante das novas possibilidades de acesso à informação, a organizaçáo escolar atual náo atende a necessidade real dos alunos, o que provoca falta de interesse pela escola, pelos conteúdos e pela forma como os professores conduzem suas aulas. As informaçóes assim veiculadas servem, em alguns casos, de ferramenta para colocar em cheque o saber do professor e seu papel como "dono da verdade". De outro, o professor, muitas vezes, distante dessas novas linguagens, se sente inseguro em relação ao papel de mediador do processo de questionamento, reflexáo e ressignificação dessas informaçóes, e à sua condição de ajudar os alunos a desenvolverem a capacidade de pensar e argumentar, que a nova realidade exige, pois ele próprio está perdido no mar de informaçóes e com pouca capacidade reflexiva, o que reduz sua autoridade em relação aos alunos, acirrando as tensóes entre esses atores que não mais se reconhecem (Montero, 2001). 
Encontra-se bastante difundida, entre os professores, a percepção de que os alunos estão cada vez mais desinteressados pelos estudos e reconhecendo menos a sua autoridade. A "indisciplina", fenômeno muito referido, mas pouco refletido pelos professores, passou a ser vista como grande obstáculo ao processo educativo. Os alunos também se sentem desrespeitados pelos professores e consideram suas "aulas" monótonas e sem sentido. À vista dessas representaçóes mútuas, a aprendizagem, que deveria ser a razáo central do encontro desses atores no contexto escolar, fica bastante comprometida, como evidenciam diversos estudos (Sobrinho, 1998; Nuernberg, 1999, entre outros).

Esses estudos sinalizam a necessidade de mudanças da qualidade da relaçáo professor-aluno de forma a torná-la dialógica e afetiva em proveito do desenvolvimento integral dos sujeitos. Tal transiçâo precisa ser liderada pelos professores, por meio de um processo de mediaçáo de aprendizagens significativas, tanto do ponto de vista cognitivo quanto atitudinal, portanto, implica a mudança de suas representações sobre a funçáo social da escola, de suas concepçóes sobre o papel do professor, do aluno, de ensino e de aprendizagem. Refletir sobre esse assunto implica encontrar uma resposta para a questáo: a formaçáo de professor tem contribuído para desenvolver saberes e competências capazes de engendrar aprendizagens significativas e novas formas da relação professor-aluno?

A legislaçáo sobre a formação de professores, formulada nas últimas décadas, evidencia uma maior preocupaçáo governamental na perspectiva da profissionalização. Em consonância com essa perspectiva, a educação superior é definida como lócus principal dessa formação, portanto, mais voltada para o contexto da prática docente. Conforme a Lei de Diretrizes e Bases da Educação Nacional - LDBEN n. 9.394/96, a formação de profissionais da educação, dos diferentes níveis e modalidades de ensino, deve assegurar, aos formandos, o domínio das características de cada fase do desenvolvimento do educando e ter como princípio a associaçáo entre teoria e prática (Brasil, 1996).

Embora a formação de professores seja abordada de forma muito lacônica na citada lei, elementos apresentados em diversas partes do seu texto servem de referência para o processo de formação docente, em especial no que concerne à relação professor-aluno no processo de ensino-aprendizagem. Na seção do ensino fundamental, apontam-se, entre outros, os objetivos desse nível de ensino: o desenvolvimento da capacidade de aprendizagem, com vistas à aquisiçáa de conhecimentos, habilidades e de atitudes e valores, e o fortalecimento dos laços de solidariedade humana e de tolerância recíproca que, no dizer do texto legal, sustenta a vida em sociedade. Tais aspectos 
reforçam a perspectiva do ensino centrado na aprendizagem e nas necessidades dos alunos, o que sugere novas formas de relação entre esses e os professores.

O Plano Nacional da Educação, Lei n. 10.172/2001, estabelece a obrigatoriedade de formação superior para os professores em exercício que têm até o curso normal, ao mesmo tempo em que exige o aumento da qualidade da aprendizagem dos alunos, reconhecendo que o processo de ensino-aprendizagem vai além da transmissáo de informaçôes, centra-se, em contrapartida, no sujeito que aprende. A exigência da formaçáo em nível superior dos docentes em exercício cria uma situaçâo que implica a vivência, simultânea, de uma dupla condição, por parte desses sujeitos: de professor e de estudante 1 , que, naturalmente, coloca novos desafios para a formação e para esses sujeitos, enquanto estudantes, na sua relação com a aprendizagem e com os professores-formadores e, enquanto docentes, na relaçáo com seus alunos no processo de mediação de suas aprendizagens.

O texto das Diretrizes Curriculares Nacionais para o Curso de Pedagogia póe, no centro da discussão, a formação de professores como determinante para o desenvolvimento do ensino da educação básica e da aprendizagem do aluno. Assim, no seu Art. $2^{\circ}$, afirma que a formação inicial para o exercício da docência na educação infantil e nos anos iniciais do ensino fundamental deve ser construída

[...] em relações sociais, étnico-raciais e produtivas, as quais influenciam conceitos, princípios e objetivos da Pedagogia, desenvolvendo-se na articulação entre conhecimentos científicos e culturais, valores éticos e estéticos inerentes a processos de aprendizagem, de socialização e de construção do conhecimento, no âmbito do diálogo entre diferentes visóes de mundo. (Brasil, 2006, s.p.)

Embora contribuam para o estabelecimento de novas bases na relação professor-aluno, principalmente quando afirmam a aprendizagem, e náo o ensino, como centro dessa relaçáo, e a importância do respeito a valores éticos e à diversidade, as peças legais referidas não assumem essa questão explicitamente, subestimando a sua complexidade, tecida na longa história da escola centrada no ensino transmissivo de conteúdos dogmatizados e em relaçóes autoritárias.

A despeito dos novos desafios para a escola e para os professores, parte deles explicitada na legislação educacional das últimas décadas, a formaçáo inicial de

\footnotetext{
${ }^{1}$ Diante do fato de os termos aluno e estudante indicarem a mesma condição, neste artigo será usado aluno para referir-se aos discentes da educaçáo básica e estudante quando se tratar dos discentes de ensino superior.
} 
professores no Brasil, como indicam diversos estudos (Barros, 1987; Youssef, 2000; Miranda, 2005; Matos, 2005; Feitoza; Cornelsen; Valente, 2007; Cunha, 2007), ainda adota uma concepçáo de ensino notadamente cognitivista, centrada nos princípios da racionalidade técnica, que prima pelo excesso de informaçáo e de conhecimento pela via da transmissão, e pauta-se em relaçóes professor-estudantes hierarquizadas e formais.

Os trabalhos em foco apontam que relaçóes professor-estudante hierarquizadas, distantes, autoritárias concorrem para o desinteresse, para a falta de investimento e de confiança do estudante na explicitação e superação de dúvidas, o que compromete a aprendizagem. Entretanto, poucos estudos investigam a repercussão na relaçáo professor-estudante do ensino transmissivo, que dissocia teoria e prática e que cobra, dos estudantes, uma aprendizagem mecânica e memorística. Em outros termos, como a ausência de formas de ensinar capazes de gerar aprendizagens significativas interfere na qualidade da relaçáo professor-estudante no processo de formaçáo para a docência, aspecto que parece ser decisivo, considerando que a aprendizagem é o que justificaria o encontro entre professor e estudantes. Assim, constituiu-se como problema deste estudo a contribuiçâo da formação inicial de professores, no contexto da educaçáo superior, para a mudança da representação acerca da relação professor-aluno e do papel da aprendizagem significativa na melhora dessa relação de estudantes de Pedagogia, professores em exercício.

Tal estudo, situado no campo da formaçáo de professor e da pedagogia universitária, buscou compreender as representaçóes de estudantes de Pedagogia sobre a relaçáo professor-estudante no seu processo formativo. A escolha das representaçóes sociais, uma forma de pensamento que inclui informaçóes, experiências, atitudes, conhecimentos e opiniōes acerca de determinado objeto ou fenômeno, construídas nas trocas sociais, como meio de compreender os sentidos que os estudantes concluintes do Curso de Pedagogia, professores em exercício, atribuem à relaçáo entre eles e os professores formadores no âmbito do ensino superior, foi motivada, em primeiro lugar, pelo fato de essas representaçóes se constituírem, como sugere Moscovici (2003), em potentes guias das práticas sociais, neste caso, práticas educativas. Ao conhecer essas representaçóes poder-se-á inferir sobre a relação estabelecida com seus próprios alunos da educação básica e verificar se a formaçáo que vem sendo oferecida contribui para mudanças na sua prática docente. Além disso, essa abordagem contempla, no seu referencial, a possibilidade de compreender, de forma integrada, tanto os fenômenos sociais mais amplos quanto outros específicos do contexto da sala de aula. 
A pesquisa, de natureza qualitativa, adotou as técnicas: memorial e entrevista semiestruturada como formas de coleta dos dados, pois as representaçóes sociais, conforme Jodelet (1989), presentes nos discursos, são construídas, disseminadas e materializadas, principalmente pela linguagem, e são cristalizadas nas condutas. Assim, discursos e condutas constituem as principais formas de atualizaçáo dessas representaçóes. Entretanto, a linguagem tem figurado como o principal meio de acesso às representaçóes. As técnicas escolhidas, seguindo essa tradiçáo, privilegiaram a expressáo verbal dos sujeitos, a expressão escrita e a expressâo oral. Esses instrumentos, além de captar os discursos, permitiram acessar como os sujeitos compreendem suas práticas, na medida em que foi relativamente a essas que os participantes formularam suas respostas, pois, como afirma Abric (1994), as representaçóes, as práticas e os discursos sáo partes de um todo que não podem ser dissociados. Os dados foram tratados com base na técnica de análise de conteúdo de Bardin (2000). Os sujeitos foram cinco estudantes concluintes do Curso de Pedagogia de uma universidade pública da Bahia, em exercício docente na educação básica. Quatro do sexo feminino e um do sexo masculino, situados na faixa etária de 30 a 45 anos. Todos têm entre 12 e 20 anos no exercício da docência; quatro atuam no ensino fundamental e um no ensino médio. A maioria trabalha apenas como professor, um atua também como coordenador pedagógico, e outro assume a gestáo da unidade escolar.

\section{EXPLORANDO CONCEITOS: APRENDIZAGEM E RELAÇÃO PROFESSOR-ALUNO}

É possível compreender a aprendizagem sob duas perspectivas: a associativa e a construtiva. Conforme Pozo (2004, p. 20-21)

Os modelos de aprendizagem associativa, em geral, baseiam-se num enfoque elementarista, analítico, que decompóem qualquer ambiente num conjunto de elementos associados entre si com distinta probabilidade, de modo que aprender é detectar, com maior precisão possível, as reaçôes de contingência entre esses elementos ou fatos. [...] As teorias construtivistas, em contrapartida, aceitam um enfoque holista, organicista e estruturalista, pois vinculam a aprendizagem ao significado que o organismo atribui aos ambientes que têm diante de si, em funçáo das estruturas cognitivas e conceituais, a partir das quais interpreta esse ambiente.

As teorias construtivistas consideram os sujeitos em seus processos cognitivos, contemplando os conhecimentos prévios que possuem, específicos de cada um, vis- 
to que construídos a partir de seu contexto social, cultural e de suas experiências de vida. A aprendizagem é, pois, um processo no qual o sujeito, simultaneamente, constrói conhecimento e se constrói enquanto sujeito do conhecimento.

Aprendizagem e ensino são aspectos distintos; o primeiro, desenvolvido pelo estudante e o segundo, pelo professor, mas deveriam ser complementares de um único processo: a formaçáo. O termo ensinar, conforme Masetto (2003, p. 35), é associado a "instruir, comunicar conhecimentos ou habilidades, fazer saber, mostrar, guiar, dirigir", açóes próprias do professor. O termo aprender significa "buscar informaçóes, rever a própria experiência, adquirir habilidades, adaptar-se às mudanças, descobrir significado nos seres, nos fatos, nos fenômenos e nos acontecimentos" (2003, p. 36).

Em tese, a aprendizagem é a razão de ser da relação professor-aluno. Assim, o encontro entre esses dois atores só se justifica porque existe a necessidade das novas geraçóes aprenderem, no caso da formação de professor, a ser professores. Entretanto, como é sabido, náo existe uma perspectiva única de conceber a aprendizagem, nem o papel do professor e do estudante para que ela aconteça.

Masetto (2003, p. 23) defende a ideia: "a docência existe para que o aluno aprenda”. A ênfase no ensino ou na aprendizagem fará com que os resultados da relação professor-estudante sejam completamente diferentes. No ensino superior, a ênfase deve ser dada às açôes do estudante para que ele possa aprender o que se propóe, "além dos conhecimentos necessários, habilidades, competências e análise e desenvolvimento de valores" (2003, p. 23).

Para Zabala (1998), colocar o estudante no centro do processo educativo náo significa situar os professores num papel secundário, e sim evidenciar que o professor tem como objetivo central de sua atividade promover a aprendizagem. Numa concepçáo construtivista, seu papel se concentra em promover a reflexão como um processo mental intrínseco ao estudante, portanto, em favorecer a construçáo da autonomia intelectual desse sujeito.

A relaçáo professor-aluno é facilitada quando se estabelece a partir da autoridade pedagógica na qual o professor tem consciência de suas limitaçóes e trabalha no sentido de superação da autoridade própria da condiçáo profissional, o que "não significa sua eliminaçáo, uma vez que a intervençáo do educador conserva-se modificada no raciocínio elaborado pelo aluno, que se sente respeitado como partícipe do processo de ensino-aprendizagem" (Zuin, 2008, p. 37).

A interaçāo professor-aluno, saudável, complementar, dialógica, só é possível se o professor investe na aprendizagem significativa do estudante, se busca todos os 
meios de conquistar o estudante para o desafiante processo de se abrir para o novo, de ressignificar as marcas da omissão, da passividade e da memorizaçáo, de construir conhecimentos e atitudes de forma ativa e autônoma. Assim, facilitar aprendizagens conscientes sobre atitudes e valores é uma tarefa a ser assumida pelo formador de professores. Isso implica, conforme Gonzalez Rey (1995, p. 104), ter em conta o contexto afetivo relacional, na medida em que

Los valores se forman en la comunicación interpersonal, no solo por la racionalidad implicada en este proceso, sino también por la calidad afectiva que se establezca, definida por las emociones vivenciadas y el desarrollo de la sensibilidad del sujeto hacia diferentes aspectos de la vida. ${ }^{2}$

Torna-se necessário, portanto, que o professor preste,

[...] tanto quanto for possível, o acompanhamento dos processos que os alunos e alunas vão realizando na aula. $\mathrm{O}$ acompanhamento $\mathrm{e}$ uma intervenção diferenciada, coerentes com o que desvelam, tornam necessária a observação do que vai acontecendo. (Zabala, 1998, p. 90-91)

A relação professor-aluno na universidade é marcada, conforme Zuin (2008), por sentimentos ambíguos que vão desde a identificação via idolatria à total aversão das práticas docentes. A natureza conflituosa dessa relação é pautada na ironia afetiva, conforme o conceito socrático de ironia - modo de interrogar pelo qual se leva o interlocutor ao reconhecimento da sua própria ignorância - ou no ódio promovido pelo sarcasmo do professor. Para fugir desse sarcasmo, se estabelece uma relação professor-aluno baseada num fingimento conjunto em que, no seu processo formativo, o estudante transforma seu ódio, gradativamente, em um jogo de cena.

$\mathrm{O}$ docente, à medida que faz uso da soberba intelectual, contribui para que o estudante permaneça numa posição passiva no seu processo formativo. É fato que a relaçáo professor-estudante está assentada no controle de um agente sobre o outro e que, a depender da concepção de sociedade e de homem que se deseja contribuir para formar, o outro será considerado subordinado, implementando uma relaçáo de poder marcada pelo autoritarismo, ou será percebido como sujeito ativo, acionando a autoridade epistemológica do professor.

2 "Os valores se formam na comunicação interpessoal, não só pela racionalidade implicada neste processo, mas também pela qualidade afetiva que se estabelece, definida pelas emoçóes vivenciadas e o desenvolvimento da sensibilidade do sujeito em diferentes aspectos da vida." 
Nóvoa (2002, p. 23) aponta que uma das dimensóes da complexidade do ensino é a relação com o educando, pois, diverso do que acontece com outros profissionais "o trabalho do professor depende da colaboração do 'aluno'. [...] Ninguém ensina quem não quer aprender." Depreende-se, pois, que formar o profissional professor e sua profissionalidade, entendida como os saberes constitutivos da docência que $o$ professor mobiliza de acordo com as necessidades reais, é formar para a análise, a crítica, a investigaçâo e para a reflexão, além de um intenso e contínuo trabalho de motivaçáo dos educandos.

A formação de profissionais com autonomia e com motivação para aprender continuamente pressupóe que a relaçáo professor-aluno tenha, como foco, a aprendizagem construtiva do estudante, e seja baseada na confiança, na disposiçáo e na capacidade de aprender. Portanto, o investimento nessa aprendizagem e o desenvolvimento de uma relaçáo afetiva entre professor e estudante são aspectos do processo formativo que mantêm uma interação dialética e de influência mútua. O impacto dessa interação na identidade profissional do formando está diretamente ligado à possibilidade de o estudante vivenciar essa interaçâo na sala de aula da universidade.

\section{O QUE DIZEM OS DADOS...}

As representaçóes dos participantes da pesquisa acerca da relação professor-aluno atribuem importância fundamental ao empenho de ambos os atores no processo de aprendizagem. O investimento do professor na aprendizagem do estudante, de acordo com a totalidade dos participantes, se expressa na atitude de despertar o interesse para a aprendizagem, respeitando as diferenças individuais. Tal perspectiva aproxima os depoentes das formulaçôes de González Rey (2008) quando afirma que a aprendizagem é um processo singular do sujeito em que o mesmo se apropria do conhecimento, a partir das experiências vivenciadas, evitando que se torne um conjunto de saberes que náo tenha referência significativa com seus conhecimentos prévios.

Nesse sentido, a aprendizagem implica, para o professor, "lidar, de forma democrática, com a diversidade individual e cultural" (Pinto, 1999, p. 47) presente nos grupos, com a finalidade de possibilitar a individualizaçáo do processo de aprender. Isto pressupóe, segundo a maioria dos colaboradores, a necessidade de o professor estabelecer um diálogo que lhe permita compreender as causas da "falta de interesse" dos estudantes pelos seus estudos. O contato individual, de acordo com González Rey (2008, p. 40), "além de estimular a reflexão, favorece o compromisso do aluno com sua própria aprendizagem". Trata-se de um recurso que pode ajudar 
cada estudante a encontrar-se consigo mesmo, a refletir sobre sua participação no processo de produçáo do conhecimento e de formação profissional. E, ao professor, identificar os aspectos que obstaculizam a participação ativa na construção da própria aprendizagem. A participaçáo do estudante é essencial para que se processe uma aprendizagem significativa, pois, conforme diversos autores (Nunes; Silveira, 2009; Pozo, 2004; Weisz, 2004), ela possibilita uma ressignificação por meio de uma associação de novas aprendizagens com elementos de sua vivência.

$\mathrm{O}$ investimento do professor na participação e, portanto, na aprendizagem do estudante, expressa-se ainda na adoçáo de metodologias diversificadas, conforme a totalidade dos participantes. A organização de variadas situaçóes didáticas permite aproximar o ensino da aprendizagem ao contemplar, mais facilmente, a heterogeneidade do grupo da sala de aula (Ambrosseti, 1999). A ênfase na participação pressupóe a crença em que é na construção da síntese por intermédio da oralidade que se percebem os elementos apreendidos conceitualmente pelos estudantes, possibilitando retomadas e ajustes no ensino. Anastasiou e Alves (2004) apontam a necessidade de uma mudança na organização das aulas no ensino superior, ultrapassando a ação de "assistir aula" em direção ao fazer aulas, no sentido da elaboração do conhecimento com a "realização de diversas operaçóes mentais, num processo crescente de complexidade do pensamento" (p. 74). Segundo as autoras, a expressão verbal dos estudantes é fundamental para o seu desenvolvimento cognitivo, assim como promove o sentimento de pertencimento ao grupo da sala de aula, o que, por sua vez, facilita a aprendizagem.

O compromisso do professor com a aprendizagem dos estudantes, conforme a maioria dos colaboradores da pesquisa, se concretiza, também, na prática sistemática de fornecer o feedback operativo sobre as produçóes dos estudantes. Sendo a aprendizagem um processo construtivo que promove novas formas de conhecer com base nas experiências dos próprios estudantes, é fundamental que o professor não se restrinja à atribuição de conceitos ou notas. O feedback representa um instrumento importante para a aprendizagem, pois coloca o sujeito como centro da sua própria formação. De acordo com Masetto (2003), esse processo avaliativo, baseado na "retroinformaçáo" e na ajuda, deve acompanhar, de forma contínua, a aprendizagem dos estudantes.

Envolver-se na aprendizagem do estudante pressupóe, de acordo com a maioria dos participantes, que o professor tenha uma atuação que seja referência para os formandos, sem, contudo, se colocar como dono do saber. Essa compreensão remete ao princípio do isomorfismo entre a formação oferecida ao formando e o tipo de edu- 
caçáo que se espera que ele desenvolva (Marcelo Garcia, 1999), naturalmente levando-se em conta as diferentes necessidades didáticas de cada um dos contextos em questão. Isso porque, como formula Fernandez Perez (1992, apud Marcelo Garcia, 1999, p. 29), “em matéria de formaçáo de professores, o principal conteúdo é o método através do qual o conteúdo é transmitido aos futuros ou atuais professores". É fundamental a coerência entre a forma como o professor trabalha o conhecimento, o conhecimento didático do conteúdo e o conhecimento pedagógico transmitido.

Investir na aprendizagem do estudante na perspectiva da sua profissionalizaçáo envolve, na visáo da totalidade dos participantes, promover a reflexáo e a articulação dialética entre a teoria e a prática, entendidas como aspectos distintos, mas que se complementam na formação do professor, pois um não tem sentido sem o outro. A distância entre o conhecimento teórico e o prático na formação vivenciada, de acordo com a totalidade dos sujeitos, contribui para a existência do sentimento de desânimo com a formação. Pimenta e Anastasiou (2002) defendem que a experiência profissional deve ser tomada como elemento importante para a construçáo do conhecimento docente, pois é "através da reflexão, análise e problematização desta, e o reconhecimento do conhecimento tácito, presente nas soluçóes que os profissionais encontram em ato" (p. 19).

O cuidado com a aprendizagem do estudante, na visáo de quase todos os depoentes, pressupóe que o professor assuma o papel de facilitador da interaçáo dos estudantes, intervindo no sentido de ajudar a dissolver os subgrupos fechados (as famosas "panelinhas"), de gerir conflitos, promover o diálogo entre as partes e estimular a abertura para a escuta coletiva. Tais consideraçóes, carregadas de sentimentos, evidenciam a falta que sentem desse tipo de intervenção na educaçáo superior, centrada na transmissão de conteúdos "científicos", desconsiderando a possibilidade de construção de valores e atitudes e o grupo como o cenário do processo ensino-aprendizagem. No sentido apresentado pelos participantes, o professor assumiria, como sugere Filloux (1979, apud Souto de Asch, 2007, p. 62), "El rol de facilitador y elucidador de problemas técnicos o afectivos en el grupo", em síntese, o papel de mediador, também, da comunicaçáo dos integrantes do grupo da sala de aula. Valorizar a interação pressupóe o reconhecimento de que parte importante do conjunto da aula vai além das questóes conceituais e abraça a formação integral do indivíduo.

Como anunciado anteriormente, a relaçáo professor-aluno, na visão da quase totalidade dos participantes, é facilitada, também, pelo compromisso e investimento pessoal do estudante com sua própria aprendizagem Essa proposiçáo aproxima os 
participantes das consideraçóes de González Rey (2008) sobre o estudante como sujeito no processo de aprendizagem e "leva a uma organização própria e diferenciada do material aprendido, o que implica em erros nesse percurso" (p. 41).

Para a totalidade dos pesquisados, comprometer-se com a própria aprendizagem significa não se deixar abater pela dificuldade de compreensão dos conteúdos trabalhados, confrontando o sentimento de impotência, buscando ajuda. Tal movimento implica uma atitude resiliente, entendida como a "capacidade humana para enfrentar, vencer e ser fortalecido ou transformado por experiências de adversidade" (Melillo; Ojeda, 2005, p.15).

O progresso na própria aprendizagem profissional depende, para a quase totalidade dos participantes, da postura dos estudantes em relação aos resultados apontados pelos professores como insuficientes. A não-disposição para rever suas produçóes, como os dados também indicam, é resultado de uma construçáo ao longo da trajetória escolar acerca do significado de aprendizagem, do papel do estudante na relação com o saber, consigo mesmo e com os outros. Com algumas exceçóes, durante essa trajetória, havia pouca mobilizaçáo dos participantes para aprender de forma significativa. A relaçáo com o saber era baseada na memorizaçáo e na reprodução de conhecimentos destituídos de sentido, transmitidos pelos professores, situando o aprendiz num papel passivo. Muitos reconhecem que, apesar de tentar superar o receio de se expor, fizeram poucos progressos. Esse sentimento sinaliza uma posição de dependência que dificulta o processo de construçáo da própria aprendizagem desses sujeitos, pois, segundo Rubinstein (2003, p. 33), o sujeito da aprendizagem é aquele que "tem nas mãos a condição de mudança", e essa relação decorre da história de vida de cada um e das relaçóes estabelecidas com a família e nos contextos educativos.

Rosário et al. (2008) salientam ser impossível ajudar "os alunos se estes náo participarem na construçáo de seu percurso escolar" (p. 124); isso significa, segundo os autores, que "o papel do aluno para o desfecho final das aprendizagens é mais decisivo do que o papel do docente" (p. 125). O estudante comprometido com sua formação enquanto profissional, na visão de alguns participantes, precisa ter como foco a aprendizagem e não a nota, numa perspectiva de autorregulaçáo. Autorregulaçáo da aprendizagem náo significa que o conhecimento e a aprendizagem preexistam na mente ou na personalidade do sujeito, pelo contrário, o modelo autorregulatório defende que os sujeitos exercitem algum tipo de controle sobre a sua aprendizagem em contexto, nas diferentes relaçóes e situaçóes com as quais se enfrentam nos seus percursos de vida (Schunk, 2001 apud Rosário et al., 2008). 
Apesar de compreenderem que o envolvimento do estudante favorece a aprendizagem, os participantes evidenciam o receio de se expressar oralmente na sala no sentido de esclarecer suas dúvidas e entendimentos. Superar os condicionamentos construídos na trajetória escolar é um dos grandes desafios do estudante universitário, para conseguir tirar proveito da sua formação. Coulon (2008) aponta a necessidade de eles passarem do status de aluno para o de estudante. Isso significa cuidar da própria aprendizagem sem delegar, ao professor, os objetivos da sua formação. De acordo com o autor, cabe ao estudante se apropriar de seu processo formativo, com autonomia, para seguir buscando o conhecimento profissional.

A discussão dos dados salienta, como elemento das representaçóes dos participantes, a visáo de que professores e estudantes são sujeitos ativos, cujas açóes se complementam. O professor é entendido como um agente de mediação da relação dos estudantes com o conhecimento e não essencialmente detentor de um saber descontextualizado e dogmático transmitido de forma fragmentada, apesar da afirmaçáo de que essa ainda é uma prática recorrente em sala de aula na universidade. Entretanto, a visão do estudante ativo se contradiz com posturas de dependência e submissão decorrentes, em grande parte, das experiências prévias nas quais a participação espontânea, o "erro", eram motivos de castigos e puniçóes e, consequentemente, engendraram o medo de se expor e de errar. Esses elementos das representaçóes dos participantes se ancoram nas suas trajetórias escolares em que reconhecem o professor como transmissor do conhecimento e autoridade inquestionável. Expressóes como "dezenas de exercícios repetitivos e sem sentido algum eram impostos", "as aulas eram muito expositivas e conteudistas", "a fragmentação do conhecimento", "eram palavras descontextualizadas", "não havia abertura para o diálogo" ou "o dono do saber", foram recorrentes nas falas da totalidade dos participantes.

\section{CONSIDERAÇÕES FINAIS}

Os elementos que emergiram da discussáo dos dados indicam que as representaçóes dos participantes sobre a relaçáo professor-aluno contemplam, de um lado, um discurso idealizado acerca do papel mediador do professor, cuja prática está centrada na aprendizagem do estudante e na participação ativa e comprometida do estudante, e, de outro, práticas estudantis baseadas na heteronomia, no medo de se expor e ser repreendido pelo professor, que ocupa ainda o lugar de dono do saber. Essa significaçáo, construída ao longo das vivências escolares dos participantes, foi reforçada pelas práticas vivenciadas no processo formativo na universidade que, contrariamente às teorias professadas, não se distanciaram dos 
modelos anteriormente vividos e, dessa forma, não contribuíram para a ressignificação dessas representaçóes.

O fato de exercerem a docência, anteriormente e durante a formaçáo universitária, possibilitou um processo de reflexáo, em geral fora do contexto da sala de aula da universidade, e de experimentação de mudanças nas suas práticas como docentes, inspirando-se nas teorias aprendidas, que sinalizam a possibilidade de mudança dessas representaçóes sobre a aprendizagem e a relação entre ensinante e aprendizes. Essa constatação revela a fragilidade da formação de professores na universidade, de promover mudanças significativas nas representaçóes, crenças e saberes experienciais trazidos pelos estudantes.

Os dados da investigação possibilitaram assegurar que o processo de formação de professores desenvolvido na universidade precisa oportunizar a explicitação e a reflexão dos estudantes acerca da relação professor-aluno/estudante, bem como situaçôes de aprendizagem e de relaçóes interpessoais diferentes daquelas vivenciadas pelos estudantes ao longo de sua trajetória escolar. Ficou evidenciada, também, a necessidade de fortalecer o campo da pedagogia universitária como uma área importante para a reflexáo da formação dos docentes que atuam no ensino superior.

\section{REFERÊNCIAS BIBLIOGRÁFICAS}

ABRIC, J.-C. Les Représentations sociales: aspects théoriques. In: ABRIC, J.-C. (Dir.), Pratiques sociales et Représentations (p.11-36). Paris: PUF, 1994.

AMBROSSETI, N. O "Eu" e o "nós": trabalhando com a diversidade em sala de aula. In: ANDRÉ, M. E. D. A. de (Org.). Pedagogia das diferenças na sala de aula. Campinas: Papirus, 1999, p. 81-106. ANASTASIOU, L.; ALVES, L. (Org.). Processos de ensinagem na universidade: pressupostos para as estratégias de trabalho em aula. 3. ed. Joinville: Univille, 2004.

BARDIN, L. Análise de conteúdo. Lisboa: Edições 70, 2000.

BARROS, D. Proposta de uma abordagem humanista na pedagogia do ensino superior. 1987. 198 p. Dissertação (Mestrado em Educação) - Fundação Getúlio Vargas, Rio de Janeiro. Disponível em: <http://www. periodicos.capes.gov.br/portugues/index.

jsp>. Acesso em: 15 fev. 2008.

BRASIL. Ministério da Educação e Cultura. Diretrizes curriculares nacionais para o curso de pedagogia. Brasília, DF: MEC/CNE, 2006.

. Lei n. 10.172, de 09 de janeiro de 2001. Plano Nacional de Educação. Brasília, DF: MEC, 2001.

Lei n. 9.394, de 20 de dezembro de 1996. Estabelece as Diretrizes e Bases da Educação Nacional. Brasília, DF: MEC, 1996.

COULON, A. A Condição de estudante: a entrada na vida universitária. Tradução Georgina Gonçalves dos Santos, Sonia Maria Rocha Sampaio. Salvador: EDUFBA, 2008.

CUNHA, M. I. O Bom professor e sua prática. 19. ed. Campinas: Papirus, 2007.

ENGUITA, M. A Face oculta da escola: educação e trabalho no capitalismo. Tradução Tomaz Tadeu da Silva. Porto Alegre: Artes Médicas, 1989. 
FEITOZA, L.; CORNELSEN, J.; VALENTE, S. Representação do bom professor na perspectiva dos alunos de arquivologia. Perspect. ciênc. inf., Belo Horizonte, v. 12, n. 2, ago. 2007. Disponível em: <http://www.scielo. $\mathrm{br} / \mathrm{scielo}$.php?script $=$ sci_arttext $\&$ pid $=\$ 141393$ $62007000200010 \& \operatorname{lng}=e n \& \mathrm{nrm}=\mathrm{iso}>$. Acesso em: 11 fev. 2009.

GONZÁLEZ REY, F. O Sujeito que aprende: desafios do desenvolvimento do tema da aprendizagem na psicologia e na prática pedagógica.In:TACCA, M.C.V.R.Aprendizagem e trabalho pedagógico. 2 ed. Campinas, SP: Editora Alínea, 2008.

\section{Comunicación, personalidad}

y desarollo. Havana: Editorial Pueblo y Educación, 1995.

JODELET, D. Représentations sociales: um domaine em expansion. In: (Dir.). Les Représentations Sociales. Paris: PUF, 1989, (p.31-61).

MARCELO GARCIA, C. Formação de professores: para uma mudança educativa. Tradução Isabel Narciso. Porto: Porto, 1999.

MASETTO, M. Competência pedagógica do professor universitário. São Paulo, 2003.

MATOS, A. A Trajetória de aprendizagem no ensino superior. 2005. 1000 p. Tese (Doutorado em Educação) - Pontifícia Universidade Católica do Rio Grande do Sul, Porto Alegre. Disponível em: <http://www.periodicos. capes.gov.br/portugues/index.jsp $>$. Acesso em: 15 fev. 2008.

MELILLO, A.; OJEDA, E. (Orgs.). Resiliência: descobrindo as próprias fortalezas. Trad. Valério Campos. Porto Alegre: Artmed, 2005.

MIRANDA, A. Vínculo aluno-professor na atualidade: um estudo psicológico com universitários. 2005. 194 p. Tese (Doutorado em Psicologia) - Pontifícia Universidade Católica de Campinas, São Paulo. Disponível em: <http://www.periodicos.capes.gov.br/ portugues/index.jsp>. Acesso em: 15 fev. 2008. MONTERO, L. La Construcción del conocimiento profesional docente. Rosário - Santa Fe, Argentina: Homosapiens. 2001.

MOSCOVICl, S. Representações sociais: investigações em psicologia social. Petrópolis: Vozes, 2003.

NÓVOA, A. A Formação de professores e trabalho pedagógico. Lisboa: Educa, 2002.

NUERNBERG, H. Investigando a significação dos lugares sociais de professora e alunos no contexto de sala de aula. 1999. 101 p. Dissertação (Mestrado em Psicologia) - Universidade de Santa Catarina, Florianópolis. Disponível em: <http://www.periodicos.capes.gov.br/ portugues/index.jsp>. Acesso em: 15 fev. 2008.

NUNES, A.; SILVEIRA, R. Psicologia da aprendizagem: processos, teorias e contextos. Brasília: Liber Livro, 2009.

PIMENTA, S.; ANASTASIOU, L. Docência no ensino superior. São Paulo: Cortez, 2002, v. 1.

PINTO, N. Erro: uma estratégia para a diferenciação do ensino. In: ANDRÉ, M. E. D. A. de (Org.). Pedagogia das diferenças na sala de aula. Campinas: Papirus, 1999, p. 47-80.

POZO, J. Aquisição de conhecimento: quando a carne se faz verbo. Porto Alegre, Artmed, 2004. ROSÁRIO, P. et al. Autorregular o aprender em sala de aula. In:ABRAHÃO, M.H.M.B.Professores $e$ alunos: aprendizagens significativas em comunidades de prática educativa. Porto Alegre: EDIPUCRS, 2008.

RUBISTEIN, E. O Estilo de aprendizagem e a queixa escolar: entre o saber e o conhecer. São Paulo: Casa do Psicólogo, 2003.

SOBRINHO, A. Identificando a prática disciplinar no cotidiano da sala de aula e seu papel na (de) formação do sujeito: uma abordagem foucaultiana. 1998. 103 p. Dissertação (Mestrado em Educação) - Universidade Federal do Ceará. Fortaleza Disponível em: <http//www.presidentekennedy.br/rece/ trabalhos>. Acesso em: 28 jan. 2005.

SOUTO DE ASCH, M. Hacia uma didáctica de lo grupal. Buenos Aires: Miño y Dávila, 2007. 
WEISZ, T. O Diálogo entre o ensino e a aprendizagem. 2 ed. São Paulo: Ática, 2004.

YOUSSEF, A. A Competência interpessoal e a sua importância para a qualidade do ensino superior. 2000. 125 p. Dissertação (Mestrado em Educação) - Pontifícia Universidade Católica do Paraná, Curitiba. Disponível em: <http://www. periodicos.capes.gov.br/portugues/index. jsp>. Acesso em: 15 fev. 2008.

ZABALA, A. A Prática educativa: como ensinar. Porto Alegre: ArtMed, 1998.

ZUIN, A. Adoro odiar meu professor: o aluno entre a ironia e o sarcasmo pedagógico. Campinas: Autores Associados, 2008.

Recebido em: março 2011

Aprovado para publicaçâo em: junho 2011 